\title{
Typical distribution of the solar erythemal UV radiation over Slovakia
}

\author{
A. Pribullová ${ }^{1}$ and M. Chmelík ${ }^{2}$ \\ ${ }^{1}$ Geophysical Institute of the Slovak Academy of Sciences, Stará Lesná, Slovakia \\ ${ }^{2}$ Slovak Hydrometeorological Institute, Poprad-Gánovce, Slovakia \\ Received: 3 January 2008 - Published in Atmos. Chem. Phys. Discuss.: 25 March 2008 \\ Revised: 21 July 2008 - Accepted: 12 August 2008 - Published: 10 September 2008
}

\begin{abstract}
Maps of solar erythemal ultraviolet (EUV) irradiance daily doses were created for every month with a horizontal resolution of $500 \mathrm{~m}$ at the geographical domain $47.15 \mathrm{~N}-49.86 \mathrm{~N} \times 16.94 \mathrm{E}-22.81 \mathrm{E}$ covering the territory of Slovakia. The cloud modification factor for the EUV radiation $\left(c m f_{U V}\right)$ was modeled utilizing the relation between the cloud modification factor of global and EUV radiation. The maps of the $c m f_{U V}$ factor were created by utilizing measurements of global irradiance performed at nine observatories during the period 1995-2004 and modeling of the $c m f_{U V}$ dependence on altitude. Maps of the EUV irradiance daily dose corresponded to clear-sky conditions and EUV irradiance daily dose affected by average cloudiness were constructed for mean monthly total ozone, its upper and lower monthly limits, for two probability levels of snow cover occurrence as criteria for the snow effect incorporation in the model and for one day representing typical values for every month. The map-set can be regarded as an atlas of solar EUV radiation over Slovakia.
\end{abstract}

\section{Introduction}

Solar UV radiation manifests strong biological effects on ecosystems. Overexposure to solar UV radiation can exhibit instantly (as, e.g., skin erythema), but disturbance of some physiological processes of live organisms can manifest as a consequence of large cumulative doses of UV radiation (development of skin cancers, change in the photosynthetic activity of plants) (WMO, 2003). From the latter point of view, the knowledge on typical UV climate is important. Determination of UV climate using ground or satellite measurements

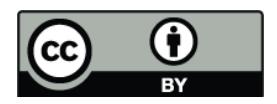

Correspondence to: A. Pribullová (apribull@ta3.sk) is usually impossible due to the restricted length of the UV radiation time-series or due to the low density of sites with the UV radiation ground measurements. Modeling of the UV radiation and spatial interpolation methods are the tools usually applied for UV climate estimation.

Several studies have been performed to determine the UV climate at different spatial scales - from local studies of UV radiation long-term variability (Lindfors and Vuilleumier, 2005) to regional analyses (Lucini et al., 2006; Meloni et al., 2000) or global UV radiation pattern determination (Herman et al., 1999). Utilizing UV radiation modeling is a possible way to obtain information on solar UV radiation in places where measurements are not performed, which is important for map representation of the UV radiation geographical distribution. UV radiation simulation can also improve knowledge on its long-term variability during time periods in the past for which no reliable measurements are available. Total ozone, cloudiness, surface albedo, information on atmospheric turbidity, sunshine duration, and global radiation are the proxies usually used as an inputs to the models. The UV index and EUV irradiance daily doses are the parameters most frequently employed for the determination of UV radiation climate (Lucini et al., 2006), but there have also been efforts to model spectral UV irradiances (Meloni et al., 2000; Bodeker and McKenzie, 1996). Comparison of EUV radiation models utilizing different input parameters and different approaches to UV radiation modeling at four European places showed that models involving global radiation as a proxy parameter provided the best results (Koepke et al., 2006).

The reliability of UV climate expressed in map form depends on UV radiation model quality, availability of model input parameters and their spatial distribution (Schmalwieser and Schauberger, 2001) and also on the interpolation method utilized for map visualization (Tatalovich, 2006).

Published by Copernicus Publications on behalf of the European Geosciences Union. 


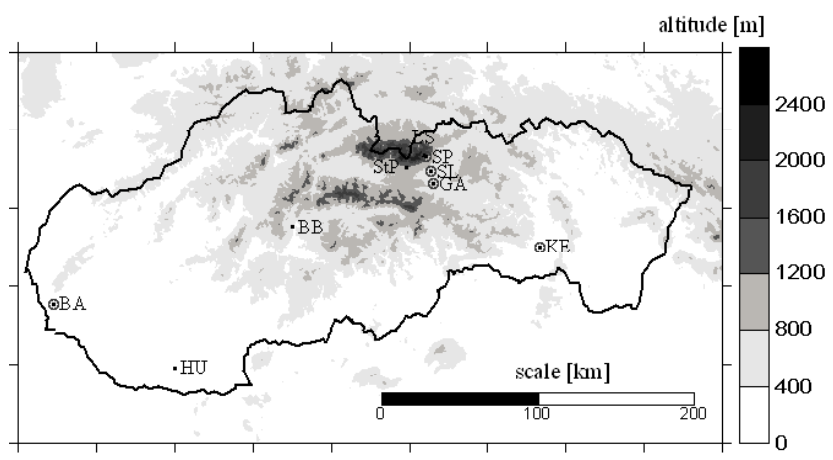

Fig. 1. Investigated territory with surface altitude and border of Slovakia. The places with measurements of global solar radiation are designated by black dots; places with EUV radiation measurements are labelled by rings. The abbreviations for observatories relate to Table 1.

The aim of this publication is to create maps of the EUV irradiance daily doses typical for the whole territory of Slovakia, employing available radiative measurements and meteorological data. The EUV radiation climate expressed in map form can be useful for future local studies on UV radiation impact on the biosphere and human beings.

\section{Material and methods}

\subsection{Data}

Solar EUV irradiance was measured at five observatories equipped with UV biometers in Slovakia (Table 1). SL501A UV biometers operate at all stations except Bratislava, which operates an SL501 UV biometer, and Stará Lesná, which operates a YES UV radiometer. The stability of all instruments has been checked by comparison with the national standard device periodically since 2002. The comparisons did not show any abrupt changes in the sensitivities of the five site instruments except for a steep decrease detected at Košice. The differences between the standard instrument and site instruments were less than $3 \%$ (for the solar zenith angle, SZA <60 ${ }^{\circ}$ ) in 2002-2004 period. The exception was the UV biometer located at Košice, where the differences were about $11 \%$ in 2003 and a rapid year to year decrease in the instrument sensitivity was observed. The relative spectral response and relative angular response were certified by the national standard device and by only one site UV biometer located at Skalnaté Pleso under the umbrella of the international COST-726 campaign at Davos in 2006.

The EUV radiation climate was estimated utilizing ancillary data from the decade 1995-2004. Measurements of global radiation performed at nine stations were utilized by this study (Table 1). CM-11 pyranometers have been operated at all the investigated stations except Stará Lesná and Skalnaté Pleso, which have been equipped with Sontag pyra- nometers. The stability of all instruments is controlled regularly against the national standard device.

The distribution of places with global radiation measurements over the territory of Slovakia is irregular. Five of nine instruments are located in a small area of the High Tatra mountains in the northern part of Slovakia (Fig. 1). However, the altitudes of observatories performing the global solar radiation measurements cover nearly the whole altitude range of the investigated geographical area, which is the reason why dependences on altitude of both EUV radiation modification by clouds and snow occurrence were parameterized to depict their spatial distribution.

Daily mean values of the total ozone and monthly climatology were obtained from measurements performed with the Brewer spectrophotometer MKIV (the spectral range of this instrument is $290-325 \mathrm{~nm}$, the resolution is $0.6 \mathrm{~nm}$, and the accuracy of the total column ozone determination from direct solar radiation measurement is 1\%) at Poprad-Gánovce in the decade 1995-2004. It was considered that the total ozone measured at Poprad-Gánovce was representative of the whole investigated area. This assumption was applied on the basis of daily and monthly total ozone comparisons between Poprad-Gánovce and surrounding stations Hradec Králové, Belsk and Budapest for period 1994-1999 (Chmelík, 2000). The standard deviation of the total ozone monthly average measured at Poprad-Gánovce from the values measured at Budapest, Belsk and Hradec Králové were of $2.7 \%, 2.4 \%$ and $1.6 \%$ (2.0\% for total ozone measured by the Dobson spectrometer at Hradec Králové), respectively. The standard deviation of the TOMS satellite monthly total ozone at Poprad-Gánovce from values at surrounding stations ranged from $1.2 \%$ to $1.5 \%$. Comparison between the TOMS satellite 1979-1994 data corresponding to to PopradGánovce and to Belsk, Budapest and Hradec Králové coordinates showed that the standard deviation of Poprad-Ganovce daily total ozone from Belsk, Budapest and Hradec Králové daily values increased to $4.9 \%, 3.9 \%$ and $5.5 \%$, respectively. The reliability of the Poprad-Gánovce daily total ozone application at the remote stations Bratislava $(250 \mathrm{~km}$ southwest of Poprad-Gánovce) and Hurbanovo (200 km south) can lead to the introduction of errors in the model. The upper limit of daily total ozone error is probably close to the differences between daily total ozone measured at Poprad-Gánovce and Budapest or Hradec Králové (4-5\%). The distance between Poprad-Gánovce and the most remote points in the model domain is around $300 \mathrm{~km}$. A total ozone error arising from usage of the uniform monthly total ozone for the whole investigated territory is comparable with the differences between monthly total ozone at Poprad-Gánovce and at Budapest or at Hradec Králové (it is less than 3\%).

An aerosol optical depth at wavelength $340 \mathrm{~nm} \mathrm{AOD}_{340}$ was set to be 0.4 . This value corresponds to the average of the $\mathrm{AOD}_{320}$ calculated from the Poprad-Gánovce Brewer spectrophotometer measurements of direct solar radiation at wavelength $320 \mathrm{~nm}$ in period 1993-2002 (Pribullová, 2002). 
Table 1. Stations utilized for the determination of EUV radiation climatology in Slovakia, their abbreviations, geographical coordinates, and time periods with available global solar irradiance $(G)$ measurements, EUV iradiance measurements (EUV), and information on snow cover.

\begin{tabular}{lccrccc}
\hline Station & $\begin{array}{c}\text { Latitude } \\
{[\mathrm{N}]}\end{array}$ & $\begin{array}{c}\text { Longitude } \\
{[\mathrm{E}]}\end{array}$ & $\begin{array}{c}\text { Altitude } \\
{[\mathrm{m} . \mathrm{a} . \mathrm{s} .1 .]}\end{array}$ & G & EUV & snow \\
\hline Hurbanovo (HU) & 47.87 & 18.20 & 135 & $1995-2004$ & n.d. & $1995-2004$ \\
Bratislava (BA) & 48.17 & 17.12 & 292 & $1995-2004$ & $2002-2004$ & $1995-2004$ \\
Košice (KE) & 48.70 & 21.27 & 230 & $1995-2004$ & $2002-2004$ & $1995-2004$ \\
Banská Bystrica (BB) & 48.73 & 19.12 & 427 & $1986-1993$ & n.d. & n.d. \\
Poprad-Gánovce (GA) & 49.03 & 20.32 & 703 & $1995-2004$ & $2002-2004$ & $1995-2004$ \\
Stará Lesná(SL) & 49.10 & 20.28 & 810 & $1995-2004$ & $2002-2004$ & $1995-2004$ \\
Štrbské Pleso (StP) & 49.12 & 20.07 & 1387 & $1995-2004$ & n.d. & $1995-2004$ \\
Skalnaté Pleso (SP) & 49.18 & 20.23 & 1778 & $1995-2004$ & $2002-2004$ & $1995-2004$ \\
Lomnický štít (LS) & 49.20 & 20.22 & 2635 & $1984-1992$ & n.d. & n.d. \\
\hline
\end{tabular}

The Angstroem's formula with exponent $\alpha=1.3$ was used for correction of the $\mathrm{AOD}_{320}$ to $\mathrm{AOD}_{340}$ required as input by the radiative transfer model.

Information on daily snow cover (snow cover thickness) was available for all stations providing global radiation measurements except Banská Bystrica and Lomnický štít. A digital terrain model DMR500-SK in SJTSK cartographic projection and resolution of $500 \mathrm{~m}$ available on the Internet (http://www.geomodel.sk/sk/download/ download.htm) was utilized for the EUV radiation map visualization. The relief altitude of the investigated territory varied in range from 50 m.a.s.l. to 2650 m.a.s.l. Maps of EUV radiation daily doses were created for every month at a geographical domain $47.15 \mathrm{~N}-49.86 \mathrm{~N} \times 16.94 \mathrm{E}-22.81 \mathrm{E}$ covering the territory of Slovakia.

\subsection{Parameterization of EUV radiation cloud attenuation}

The global radiation measurements were used as proxy data for the EUV radiation cloud attenuation modeling.

The attenuation of radiation by clouds was expressed by the cloud modification factor. The cloud modification factor was defined as a ratio of the radiation measured by any cloudiness condition over the radiation corresponding to clear-sky conditions. The attenuation of EUV radiation by clouds, $c m f_{U V}$, was modeled as a function of the global radiation cloud attenuation, $\mathrm{cmf}_{G}$, for six categories of the SZA:

$c m f_{U V}=f\left(c m f_{G}, \mathrm{SZA}\right)$.

The model of daily values of $c m f_{U V}$ is statistical. Dependence of the $c m f_{U V}$ on the $c m f_{G}$ was separately expressed by the 2nd degree polynomial function for each of the six SZA intervals. The value of SZA related to the time of solar culmination. Regression parameters were determined by using data obtained at four locations in Europe (Thessaloniki, Davos, Potsdam, Bergen) under the European action COST726 (Koepke et al., 2006). Values of global and EUV ra- diation corresponding to clear-sky conditions for modeling the $c m f_{U V}$ and $\mathrm{cmf}_{G}$ were calculated by the radiative transfer models. Daily doses of EUV irradiance corresponding to clear-sky conditions were calculated from irradiances modeled by the TUV (total ultraviolet-visible) radiative transfer model (Madronich, 1993), assuming standard atmospheric conditions (US standard atmosphere), fixed aerosol content $\left(\mathrm{AOD}_{340}\right.$ was set at 0.4 at altitude of Poprad-Gánovce), continental aerosol optical chracteristics, Eltermann's (1968) aerosol vertical profile, fixed no-snow surface albedo of 0.03 and measured total ozone. A discrete ordinate radiative transfer scheme was used. The weight function for human erythema (McKinlay and Diffey, 1987) was applied to the modeled spectral irradiances. Modeled daily doses of EUV irradiance corresponding to clear-sky conditions were corrected if snow was registered at any station. A fixed increase in EUV radiation caused by snow reflectivity of $15 \%$ was assumed (Pribullová and Chmelík, 2005).

Global irradiances corresponding to clear-sky conditions were modeled by the libRadtran radiative transfer model (Mayer and Kylling, 2005) for standard atmosphere, no-snow conditions, fixed atmospheric aerosol content expressed by a horizontal visibility of $25 \mathrm{~km}$. Daily doses of global irradiance were calculated from modeled irradiances for every place with measured global radiation. If there was snow at any station, a correction of the global radiation was performed (SZA dependent increase in global radiation in comparison with no-snow conditions was assumed) in accordance with Pribullová and Chmelík (2005) local study conclusions.

Validation of the model using the Slovak 2002-2004 daily EUV data (5 stations) showed the following results of the model: the correlation coefficient ranged from 0.96 to 0.99 , RMS error from $15 \%$ to $27 \%\left(141-190 \mathrm{~J} \mathrm{~m}^{-2}\right)$. The largest RMS error (27\%) was determined at Stará Lesná were the YES UV biometer was installed. 
Monthly means of the $c m f_{U V}$ factor $\left(c m f_{\text {UVM }}\right)$ were calculated at every place with global irradiance measurements. As places with available $c m f_{U V}$ values were distributed irregularly over the investigated territory and interpolation methods used for map visualization of the $c m f_{\text {UVM }}$ did not provide reasonable results, the dependence of the $\mathrm{cmf}_{\mathrm{UVM}}$ on altitude was fitted for every month to obtain maps of the cmf UVM distribution:

$c m f_{\mathrm{UVM}}=f(h)$

where $h$ is altitude and $f$ is 2nd degree polynomial function. The stations Banská Bystrica and Lomnický štít were excluded from the fitted vertical profile from October to June due to missing information on snow.

\subsection{Parameterization of the snow reflectivity effect on EUV radiation}

To incorporate the snow effect in the EUV radiation climate map visualization, information on the typical space distribution of the snow cover over Slovakia was required. As the stations recording the snow cover were irregularly distributed, the dependence of the snow occurrence on altitude was modeled. The monthly probability of snow occurrence was firstly determined from all available data at every station. The altitude of defined probability of snow occurrence was calculated using the linear interpolation between the altitudes of stations with the snow occurrence probabilities below and above the defined limit. Two probability limits of $50 \%$ and $70 \%$ were chosen for the determination of altitudes above which the snow effect on the EUV radiation was incorporated into the model. The higher snow probability levels were concentrated on mountains only. Snow probabilities lower than 50\% are of less interest for climatological study as they reflect not typical but less probable or extreme situations.

\subsection{Map visualization}

Typical monthly EUV radiation distribution was obtained by simulation of one day conditions characterized by an appropriate monthly total ozone, cloud attenuation conditions, and snow cover distribution. The EUV radiation map construction was performed using the following steps:

1. The daily doses of EUV irradiance corresponding to clear-sky conditions were calculated by the radiative transfer model TUV for the 15th day of every month. The calculations were performed for standard atmospheric conditions, no-snow UV albedo, fixed continental aerosol content $\left(\mathrm{AOD}_{340}=0.4\right.$ at the altitude of Porad-Gánovce) with Eltermann's (1968) vertical distribution and three categories of the total ozone (monthly average, monthly average \pm standard deviation from average). The EUV irradiance daily doses were determined for fixed altitude of 500 m.a.s.l and geographical coordinates of grid points covering the investigated area regularly $(3 \times 4$ points $)$.

2. The linear kriging interpolation method (Isaaks and Srivastava, 1989) was applied to recalculate the clear-sky EUV radiation to all grid points of the digital terrain model $(900 \times 500)$.

3. The EUV radiation recalculated for every grid point was then corrected for the altitude of every grid point. Linear change of the EUV radiation with an altitude of 15\%/1000 m (Pribullová and Chmelík, 2005) was assumed.

4. The correction of the EUV irradiance daily doses with respect to snow cover was performed at all grid points with altitudes exceeding the limit where snow incidence is observed with both $50 \%$ and $70 \%$ probabilities.

5. The maps of monthly attenuation of EUV radiation by clouds expressed by the $c m f_{\text {UVM }}$ were constructed utilising the modeled dependence of the $c m f_{\text {UVM }}$ on altitude (Eq. 2).

6. The modeled EUV irradiance daily doses corresponding to clear-sky conditions were multiplied by the $\mathrm{cmf}_{\mathrm{UVM}}$ factor modeled for appropriate altitude and month at every grid point, and maps of EUV irradiance daily doses reflecting the mean cloudiness effect were created.

Finally $12 \times 3 \times 2$ maps were created for clear-sky and cloudy conditions. Together, the maps can be regarded as an atlas of the geographical distribution of EUV radiation over the territory of Slovakia.

\section{Results and discussion}

\subsection{Attenuation of EUV radiation by clouds}

The climatology of the EUV radiation cloud attenuation was determined for every station with available measurements of the global radiation. A difference between the annual courses of the $c m f_{\mathrm{UVM}}$ at the mountain stations and at the valley and lowland stations values was detected.

The lowest $c m f_{\mathrm{UVM}}$ values, ranging between 0.45 and 0.55 , were detected at the mountain stations Lomnický štít, Skalnaté Pleso and Štrbské Pleso in July. A decrease in the cmf UvM values to 0.60 was also observed at Stará Lesná and Poprad-Gánovce (located close to the High Tatra mountains) during summer. Convective cloud formation can explain the large attenuation of EUV radiation by clouds in the mountains during the summer.

The highest values of the $c m f_{\text {UVM }}$ were observed at the mountain stations during winter (December, January). A decrease in the cloud attenuation effect with altitude in winter 
Table 2. Correlation coefficient $\mathrm{r}$ between measured and modeled values of the $c m f_{\mathrm{UVM}}$ and the relative RMS error of the modeled $c m f_{\mathrm{UVM}}$ dependence on altitude.

\begin{tabular}{lcccccccccccc}
\hline Month & 1 & 2 & 3 & 4 & 5 & 6 & 7 & 8 & 9 & 10 & 11 & 12 \\
\hline$r$ & 0.921 & 0.208 & 0.204 & 0.886 & 0.989 & 0.949 & 0.943 & 0.943 & 0.846 & 0.549 & 0.358 & 0.798 \\
RMS [\%] & 5.4 & 4.6 & 7.8 & 2.9 & 1.2 & 4.1 & 5.0 & 3.7 & 4.0 & 4.1 & 6.0 & 7.9 \\
\hline
\end{tabular}

probably relates to low cloudiness, which occurred more frequently over valleys and lowlands than high mountains. Generally, the highest annual amplitude of the $c m f_{\text {UVM }}$ detected at the mountain stations results from the typical mountain cloudiness regime - intensive convective activity in summer and more frequent clear days in winter.

The valley and lowland stations Hurbanovo, Bratislava, Košice and Banská Bystrica manifested less significant annual variability in $c m f_{\mathrm{UVM}}$ (values ranged between 0.65 and 0.70 except for November-January, when the $c m f_{\text {UVM }}$ dropped to $0.55-0.65)$.

The mean annual $c m f_{U V}$ values ranged from 0.61 at Štrbské Pleso to 0.68 at Hurbanovo. An increase in the $c m f_{\text {UVM }}$ with altitude was determined for the period October-January. A decrease in the $c m f_{\text {UVM }}$ with altitude was found from April to August. The dependence of the $c m f_{\text {UVM }}$ on altitude is less significant during September, November, February and in March, when the range of the cmf UvMvalues is small (0.68-0.75 in March) and the EUV radiation cloud attenuation is nearly uniform over the whole investigated area.

The dependence of the $c m f_{\text {UVM }}$ on altitude was modeled to find its geographical pattern. The quality of modeled dependence is summarized Table 2.

The lowest correlation coefficient between the modeled and measured data was determined for February, March, October, and November, when the $c m f_{\text {UVM }}$ did not depend on altitude significantly. The relative RMS errors are also large for January and July (5.0-5.4\%), despite relatively high correlation coefficients between measured and modeled values. The vertical profile of the $c m f_{\text {UVM }}$ is complicated and cannot be expressed by a simple increasing or decreasing function with reasonable fit quality in some months. The lowest values of the cmf UvM (lower than at Lomnický štít) observed from April to August at Skalnaté Pleso could partly relate to shadow effect and strong convective cloud formation manifesting at this place in summer. The $c m f_{\text {UVM }}$ is the lowest at Štrbské Pleso in October and November and the cmf UVM is lower at Štrbské Pleso in comparison with Skalnaté Pleso from September to April. This may be caused by the leeward position of Štrbské Pleso in the High Tatra mountains in comparison with Lomnický štít, Skalnaté Pleso and Stará Lesná, which are located in the southeast part of mountains in the rain shadow of the prevailing west winds. To model the cmf UVM distribution with high resolution, more stations with global irradiance measurements are needed. The derived de- pendence of the $c m f_{\text {UVM }}$ on altitude reflects the character of the local cloudiness regime; it probably cannot be applied generally in any mountain condition and can only be used for the altitude range of the investigated places.

\subsection{Snow climatology}

The snow occurrence probability for every month was calculated as a ratio between the number of days with snow and the total number of days. Two limit cases with snow incidence probabilities $50 \%$ and $70 \%$ were investigated.

Probabilities of snow incidence of below 50\% and 70\% were detected at all stations from June to October and from May to October, respectively. Snow incidence exceeding a probability of 50\% was found for the station Hurbanovo (representing the lowest parts of the Danubian lowland) in January only. In May, a snow probability above $50 \%$ was still detected at Skalnaté Pleso. Snow incidence was assumed for the whole investigated territory in January only.

The altitudes of defined snow incidence probability represented the limits for incorporation of the snow effect on the EUV radiation. The EUV radiation values are enhanced by the snow reflectivity in inhabited areas with altitudes around 1000 m.a.s.l. in April. The snow cover is not in populated areas in May, but people at the peak ski-resorts in the Tatra mountains can be affected by the enhanced EUV radiation due to snow.

\subsection{Maps of EUV radiation}

The maps of EUV radiation created as result of the modeling and spatial visualization methods provide information on its range and spatial distribution over the investigated territory of Slovakia. The decrease in the EUV radiation with increasing geographical latitude was expected for the area with homogeneous surface with uniform altitude. Maps of EUV irradiance daily dose corresponding to clear-sky conditions did not follow the expected pattern. As highly elevated places are concentrated in northern and central parts of Slovakia, the highest monthly values for EUV radiation were detected at these mountain peaks for clear-sky conditions, especially for the lower limits of the total ozone and snow cover presence simulated at high altitudes. Daily doses of EUV irradiance ranging between 4 and $7 \mathrm{~kJ} \mathrm{~m}^{-2}$ were detected at peaks of the Tatra mountains from May to July with a cloudless sky and for total ozone ranging \pm standard deviation from 

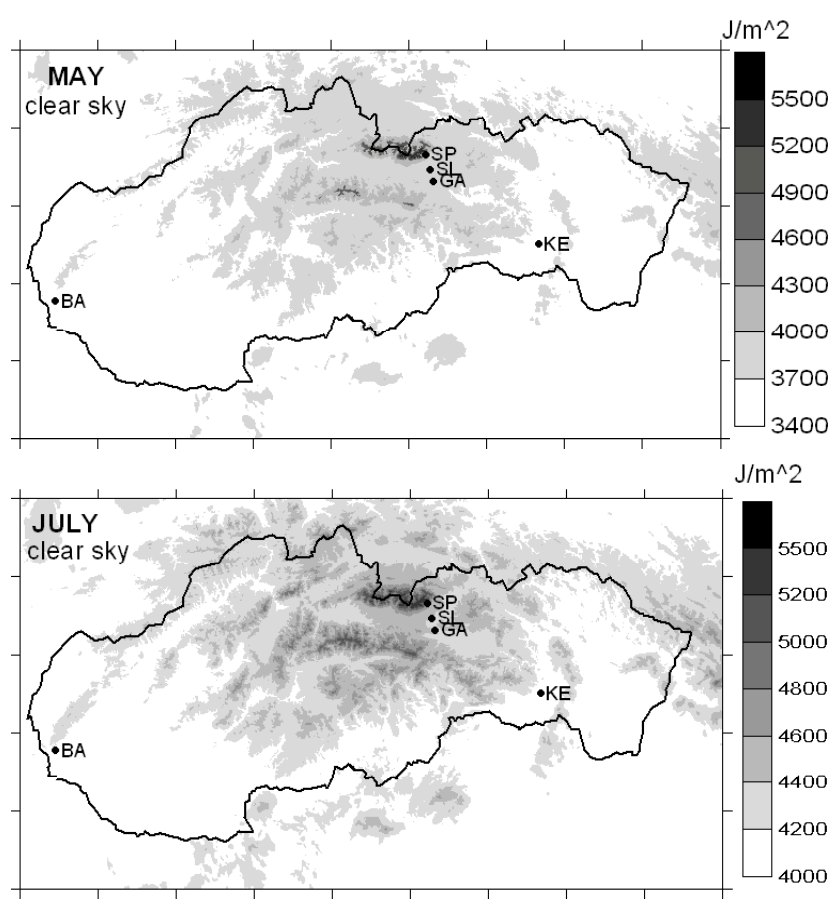

Fig. 2. Modeled clear-sky EUV irradiance daily doses for May and July. The EUV irradiance daily doses corresponding to clear-sky conditions were calculated for the 15 th day of the month and corresponding monthly average values of the total ozone and appropriate snow conditions (the surface covered by snow was assumed from altitudes with a snow incidence probability of 50\%).

its monthly average. A well-expressed increase in EUV radiation with altitude is documented in Fig. 2 for clear-sky conditions in May and July.

A homogeneous distribution of aerosol in the layer of air between the lowest and the highest positions of the investigated area with an equal vertical gradient of EUV radiation $(15 \% / 1000 \mathrm{~m})$ was assumed. Vertical gradients of the EUV radiation of $7 \% / 1000 \mathrm{~m}, 15 \% / 1000 \mathrm{~m}$ and $13 \% / 1000 \mathrm{~m}$ were simulated using the TUV model (with input parameters as in Sect. 2.2 and average Poprad-Gánovce total ozone of $325 \mathrm{DU}$ ) between Lomnický štít and Sklanaté Pleso; Poprad-Gánovce and Sklanaté Pleso and between PopradGánovce and place with altitude of 100 m.a.s.l. (and PopradGánovce geographical coordinates), respectively. The modeling showed that the assumption of a fixed vertical gradient probably causes overestimation of EUV irradiance daily doses corresponding to clear-sky conditions at the highest mountain peak positions. Comparison of model results with measurements of EUV irradiance at higher mountain positions than Sklanaté Pleso could clarify how the Eltermann's (1968) aerosol vertical distribution fits real condition in the High Tatras.

The range of the EUV radiation values decreased after incorporation of the cloud effect in the modeled EUV radiation
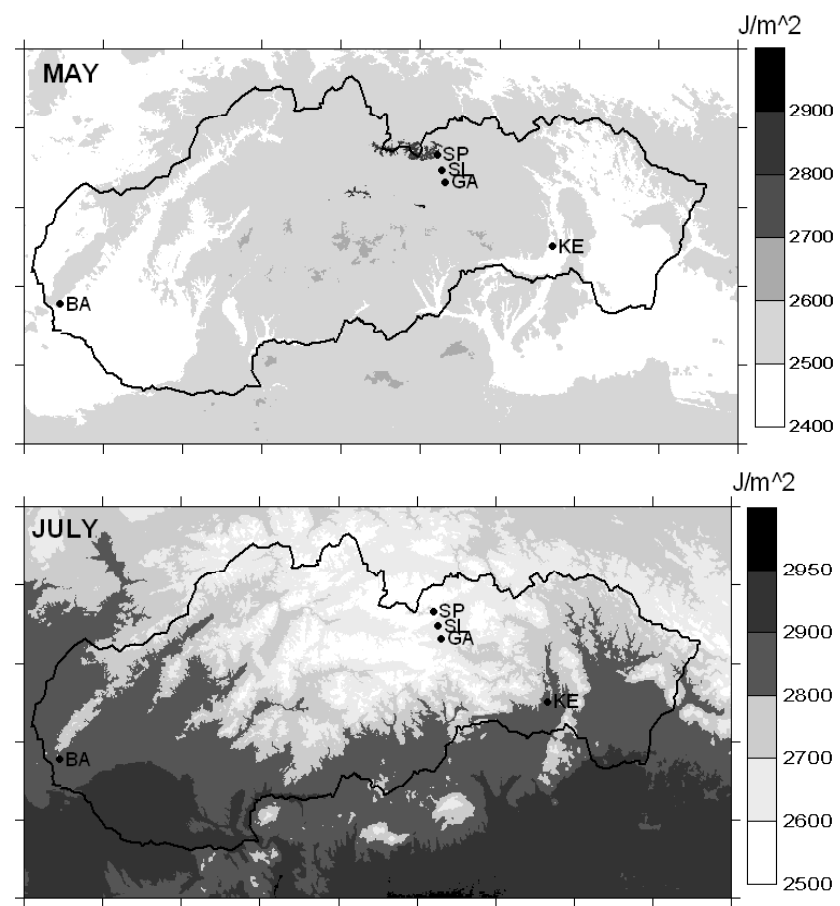

Fig. 3. Modeled EUV irradiance daily doses for May and July assuming mean attenuation by clouds. The EUV irradiance daily doses were calculated for the 15 th day of month and corresponding monthly average values for the total ozone, $c m f_{\text {UVM }}$, and appropriate snow conditions (the surface covered by snow was assumed from altitudes with a snow incidence probability of 50\%).

(Fig. 3). An increase in EUV radiation influenced by mean cloudiness with altitude was still detected from November to April, which corresponds to a vertical increase in the cmf UVM factor. But the geographical distribution of the EUV radiation did not follow the relief as it did for the clear-sky conditions.

The daily doses of the EUV irradiance attenuated by average cloudiness decrease with altitude from May to September. As can be seen in Fig. 3 for July, the highest EUV irradiance daily doses (of $3 \mathrm{~kJ} \mathrm{~m}^{-2}$ ) were detected in southern parts of the Danube and the East-Slovak lowlands. EUV irradiance daily doses about $2 \mathrm{~kJ} \mathrm{~m}^{-2}$ were found in the northern part of Slovakia with no significant differences between valleys and lower mountain positions.

The annual course of the EUV irradiance monthly means can be seen in Fig. 4 for all observatories equipped with UV-biometers. The EUV radiation modeled for clear-sky conditions and average cloudiness is presented for these stations. The modeled values were obtained by interpolation from maps for coordinates of every station. The mapped values were compared with monthly means and monthly maxima of the measured EUV irradiance calculated for the period 2002-2004. 

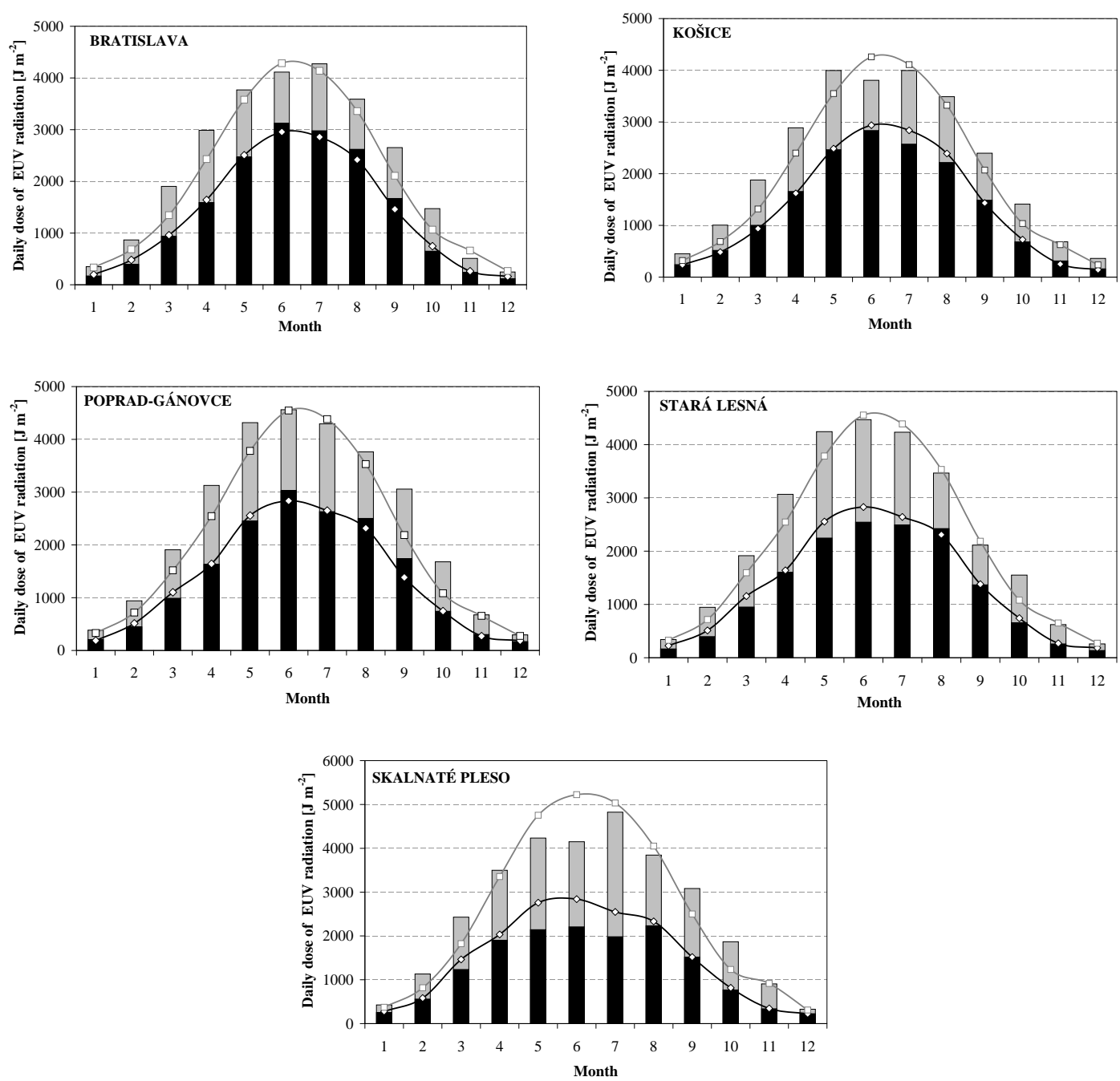

Fig. 4. Monthly mean values for EUV irradiance daily doses calculated from measured data (black columns); monthly maxima of measured EUV irradiance daily doses (gray columns); both for the 2002-2004 period at stations equipped with UV biometers; modeled EUV irradiance daily dose corresponding to clear-sky conditions (grey squares); and EUV irradiance daily dose attenuated by mean cloudiness (white diamonds). EUV radiation was modeled for average total ozone and typical snow conditions (the surface covered by snow was assumed from altitudes with a snow incidence probability of 50\%).

A difference between the monthly mean of measured EUV irradiance and the modeled values (assuming the monthly mean of the total ozone, the $c m f_{\mathrm{UVM}}$, and the surface covered by snow from altitudes with snow incidence probability 50\%) is documented in Fig. 4.

Good agreement between measured and modeled values was found in Bratislava, Košice and Poprad-Gánovce, where the relative difference between modeled and measured values did not exceed 10\% from March to August. The worst results were expected in Bratislava $(250 \mathrm{~km}$ in distance from Poprad-Gánovce, where total ozone is measured) due to uniform total ozone assumption over the whole investigated area. The summer values for EUV radiation were overestimated by the model at the Skalnaté Pleso station. The relative difference between measured and modeled EUV radiation is $28 \%$ from May to July. During the rest of the year, the modeled EUV radiation did not differ from the measured values by more than $9 \%$ (except for March, with a relative difference of $18 \%$ ). This station is strongly affected by convective clouds in summer. The main reason for the EUV radiation overestimation at Skalnaté Pleso in summer is probably error in modeling the $c m f_{\text {UVM }}$ dependence on altitude. The model did not reflect local specific conditions (shadowing, strong convection) at this station. The next source of expected errors may be interpolation from maps at Skalnaté Pleso. Skalnaté Pleso is located at the slope of the Lomnický massif where the terrain altitude changes rapidly within a small area. 
The worst results of the model were found at Stará Lesná where the relative differences between modeled and measured EUV data (22-65\% from October to March) increased with increasing SZA. The validation of the daily $\operatorname{cmf}_{U V}$ model also shows the worst results at this station, despite there being no substantial changes in instrument sensitivity detected during the comparisons with the standard UV biometer. The reason for the discrepancy could be differences between the cosine function and the angular response of this instrument. The next source of errors could be the relative spectral response of the instrument differing significantly from the action spectrum for the human erythema. These instrumental characteristics are not known. Generally, an increase in differences between measured and modeled EUV radiation was expected with a large SZA due to differences between the relative spectral response of UV biometers and the desired erythemal action spectrum. It was not detected at any station except Stará Lesná. The claimed accuracy of the broadband UV radiometers is $5-10 \%$ but with a large SZA and total column ozone the difference between measured UV irradiance and desired EUV irradiance can be significantly larger (Xu and Huang, 2003). From this point of view, the differences between measured and modeled EUV radiation are not too large. Comparison between measured and modeled EUV irradiance daily doses cannot be considered as a validation of the model. As well as model error and interpolation error, differences between the total ozone, cloudiness, and snow presence during the periods 2002-2004 and 1995-2004 can contribute to discrepancies between modeled and measured values of EUV radiation.

\section{Conclusions}

High resolution maps of EUV irradiance daily dose were created for one day of every month characterized by typical (monthly average of the cloud modification effect, average total ozone) and extreme phenomena (clear-sky conditions, upper and lower limits of the total ozone, lower and higher limits of snow incidence probability) affecting EUV radiation. EUV radiation was modeled over a small Slovak territory characterized by diverse relief. The cloud effect on the EUV radiation was simulated by statistical modeling of the EUV radiation cloud attenuation dependence on the global radiation and on the solar zenith angle. The results of local studies of the snow and altitude influence on global and EUV radiation under clear-sky conditions in the High Tatra mountains (Pribullová and Chmelík, 2005) were used for the implementation of the vertical gradient of EUV radiation and incorporation of the snow reflectance effect on EUV and global radiation. The total ozone measured at PopradGánovce was assumed to be representative of the whole investigated territory. The modeling was performed with an assumption of fixed aerosol content. 10 years climatology of the total ozone, global solar radiation, and snow cover were used for determination of the typical pattern of EUV radiation distribution over the investigated territory. The dependence of both the EUV radiation cloud modification and the snow probability occurrence on altitude was modeled for visualization of the EUV radiation in the maps.

The cloud attenuation of the EUV radiation varied from $50 \%$ in the summer to $20-25 \%$ in December-January in the High Tatra mountains. Low variability of the EUV radiation cloud modification was detected in the lowlands. The EUV radiation cloud attenuation ranged between $30 \%$ and $35 \%$ in the lowlands for the whole year except for December and January when the reduction in EUV radiation increased to $40-45 \%$. The 10 years climatology of the snow cover showed that except for winter months, when the SZA is large, a probability of snow presence of $70 \%$ was detected at inhabited altitudes at about 1000 m.a.s.l. in April. An increase in EUV radiation caused by high snow reflectivity is also probable at altitudes above 1600 m.a.s.l. where some ski-resorts provide their activities in May. The maps of the EUV radiation distribution show that the highest daily doses of $4-7 \mathrm{~kJ} \mathrm{~m}^{-2}$ can be detected at the peaks of the High Tatra mountains under clear-sky conditions from May to July. EUV radiation is reduced by clouds to values of $3 \mathrm{~kJ} \mathrm{~m}^{-2}$ in the lowlands and on the highest Tatra mountain peaks in summer. Daily doses of about $2 \mathrm{~kJ} \mathrm{~m}^{-2}$ were detected for the rest of the Slovak territory in the summer. The resulting map-set of EUV radiation modeled for average and limit conditions can be regarded as an atlas of EUV radiation over Slovakia. The maps will be available on the website of the Geophysical Institute (http://www.ta3.sk/gfu/interes.htm).

Acknowledgements. This work was supported by the Slovak Research and Development Agency under contract no. APVV-51030205, VEGA no. 2-0036-08 and by the COST-726 action.

Edited by: J. Groebner

\section{References}

Bodeker, G. E. and McKenzie, R. L.: An algorithm for inferring surface UV irradiance including cloud effects, J. Appl. Meteorol., 35, 10, 1860-1877, 1996.

Chmelík, M.: Determination of the long term total ozone average over Poprad-Gánovce station, In: Proceedings of the Quadrennial Ozone Symposium-Sapporo 2000, NASDA, Sapporo, 339340, 2000.

Eltermann, L.: UV, Visible and IR Attenuation for Altitudes to 50 km, AFCRL-680153, Air Force Cambridge Research Laboratories Environmental Research Paper, 285, Bedford, MA, USA, 68-74, 1968.

Herman, J. R., Krotkov, N., Celarier, E., Larko, D., and Labow, G.: Distribution of UV radiation at Earth's surface from TOMS measured UV-backscattered radiances, J. Geophys. Res., 104, 12 059-12 076, 1999.

Isaaks, E. H. and Srivastava, R. M.: An introduction to applied geostatistics, Oxford University Press, 561 pp., 1989. 
Koepke, P., De Backer, H., Bais, A., Curylo, A., Eerme, K., Feister, U., Johnsen, B., Junk, J., Kazantsidis, A., Krzyscyn, J., Lindfors, A., Olseth, J. A., den Outer, P., Pribullová, A., Schmalwiesser, A., Slaper, H., Staiger, H., Verdebout, J., Vuilleumier, L., and Weihs, P.: Modeling solar UV radiation in the past: comparison of algorithms and input data, in: Proceedings of SPIE, Vol. 6362 - Remote sensing of Clouds and the Atmosphere, edited by: Slusser, J. R., Schäfer, K., and Comerón, A., 636215, 2006.

Lindfors, A. and Vuilleumier, L.: Erythemal UV at Davos (Switzerland) 1926-2003, estimated using total ozone, sunshine duration, and snow depth, J. Geophys. Res., 110, D02104, doi:10.1029/2004JD005231, 2005.

Lucini, E., Cede, A., Piacentini, R., Villanueva, C., and Canziani, P. S.: Ultraviolet climatology over Argentina, J. Geophys. Res., 111, D17312, doi:10.1029/2005JD006580, 2006.

Madronich, S.: UV radiation in the natural and perturbed atmosphere, in: Environmental effects of UV radiation, edited by: Tevini, M., Lewis Publishers, Bocca Raton, 17-69, 1993.

Mayer, B. and Kylling, A.: The libRadtran radiative transfer package, Atmos. Chem. Phys., 5, 1855-1877, 2005, http://www.atmos-chem-phys.net/5/1855/2005/.

McKinlay, A. F. and Diffey, B. L.: A reference action spectrum for ultraviolet induced erythema in human skin. Human exposure to ultraviolet radiation: Risks and regulations, Elsevier Science, Amsterdam, 83-87, 1987.
Meloni, D., Casale, G. R., Siani, A. M., Palmieri, S., and Cappellani, F.: Solar UV dose patterns in Italy, Photochem. Photobiol., 71, 6, 681-690, 2000.

Pribullová, A.: Spectral UV aerosol optical thickness determined from the Poprad-Gánovce Brewer spectrophotometer observations, Contr. Geophys. Geod., 32, 3, 291-307, 2002.

Pribullová, A. and Chmelík, M.: Effect of altitude and surface albedo variability on global UV-B and total solar radiation under clear-sky condition, Contr. Geophys. Geod., 35, 3, 281-298, 2005.

Schmalwieser, A. W. and Schauberger, G.: A monitoring network for erythemally effective solar UV radiation in Austria: Determination of the measuring sites and visualization of the spatial distribution, Theor. Appl. Climatol., 69, 221-229, 2001.

Tatalovich, Z., Wilson, J. P., and Cockburn, M.: A comparison of Thiessen-polygon, Kriging and Spline Models of UV exposure, Cartogr. Geogr. Inf. Science, 33, 3, 217-231, 2006.

WMO: Scientific assessment of ozone depletion: 2002, Geneva, 2003.

$\mathrm{Xu}, \mathrm{G}$. and Huang, X.: Calibration of broadband UV-radiometers - methodology and uncertainty evaluation, Metrologia, 40, S21S24, 2003. 